
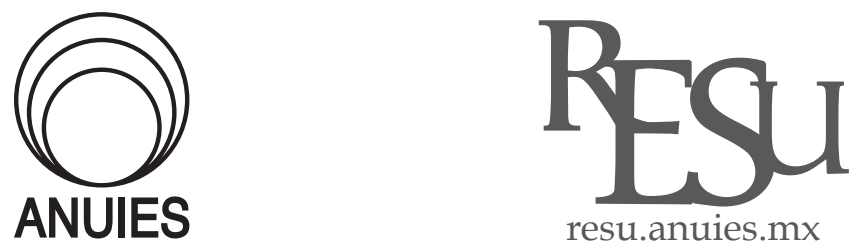

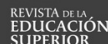

ARTí́CULO

\title{
La burocracia universitaria
}

\section{The university bureaucracy}

\section{Humberto Muñoz*}

* Universidad Nacional Autónoma de México.

Correo electrónico: hmuga@gmail.com

Recibido el 27de septiembre del 2018; aceptado el 28 de febrero del 2019.

\section{Resumen}

La burocracia universitaria conforma un grupo esencial para la operación institucional, es un actor de la política universitaria que ha crecido y consolidado su fuerza como resultado de los cambios ocurridos en las universidades públicas en los últimos años. Las tensiones en la universidad tienen muchas causas, pero una de ellas surge por la desigual distribución del poder que favorece a la burocracia frente a la comunidad académica. En suma, el propósito para que la universidad siga un buen curso es fortalecer el espíritu de colaboración de la burocracia con la academia y que sea la academia la que defina el devenir institucional mediante su participación efectiva en los cuerpos colegiados.

Palabras clave: Burocracia universitaria; Gobierno; Poder; Institución. 


\begin{abstract}
The university bureaucracy forms an essential group for the institutional operation, it is an actor of the university policy that has grown and consolidated its strength as a result of the changes that occurred in the public universities in recent years. University tensions have many causes but, one of them arises from the unequal distribution of power that favors bureaucracy over the academic community. Finally, the university purpose is to strengthen the spirit of collaboration among bureaucracy and the academy, where the academy will define the institutional development through its effective participation in the collegiate bodies.
\end{abstract}

Keywords: University bureaucracy; Government; Power; Institution.

\title{
Introducción
}

L a burocracia universitaria conforma un grupo fundamental para la operanes sociales y políticas que ocurren en la comunidad, en las relaciones y lazos con el exterior y lleva a cabo la administración. Es clave para que la universidad sea un ente organizado y funcional a sus principios y objetivos. Realiza sus tareas integrada en una jerarquía administrativa.

En México se ha estudiado poco a la burocracia universitaria (e.g. Marquis, 1987) y requerimos más análisis sistemáticos y amplios sobre este segmento de las universidades públicas. Conocer la dinámica que ha seguido su crecimiento y cómo se ha estructurado en el espacio institucional es indispensable, porque en el ámbito de la burocracia confluyen múltiples intereses para moldear la política, el gobierno y el ejercicio del poder universitario. De la burocracia puede depender la estabilidad y la gobernabilidad, o el conflicto, entre los actores que se manifiestan en el espacio universitario.

¿Qué es y cómo se comporta la burocracia? En los términos de Weber, ${ }^{1}$ la burocracia es un sistema racional en el que se ejerce la dominación conforme a leyes, dentro del cual puede haber liderazgos y costumbres que intervienen

\footnotetext{
${ }^{1}$ Max Weber escribió un estudio cuyo título es una pregunta: ¿Qué es la burocracia? Ahí hay un desarrollo amplio del concepto y una teoría social de la organización burocrática. Véase la bibliografía al final donde se señala el sitio de Internet en el que se puede consultar la obra.
} 
en las conductas que asume el grupo. Conductas que están vinculadas a un ethos burocrático, que es importante tener en cuenta en el análisis, referido al sentido de las jerarquías y la obediencia. En esta visión, la burocracia tiene valores orientados a mantener el buen funcionamiento de la organización institucional. La administración burocrática, desde esta perspectiva, tiene rasgos positivos, porque su ética no discrimina a quien hace trámites, responde puntualmente a las demandas, es confiable e imparcial en cada asunto, suprime los favoritismos y, en suma, vela por el buen ejercicio del gobierno. ${ }^{2}$

Una burocracia que soporta el manejo de una institución requiere, otra vez en los términos de Weber (2008), tener precisión, hacer cálculos, por ejemplo, del tiempo que tarda un trámite, provocar confianza en el público que lleva a cabo el trámite. La burocracia cumple con hacer coherente los medios (su trabajo) con los objetivos institucionales. O sea, tiene que ser eficaz y eficiente, ágil en el manejo de los trámites que importan al funcionamiento de una institución, lo cual otorga certeza, credibilidad y hasta legitimidad. La burocracia debe ser un apoyo para lograr lo que se pretende. Por ejemplo, en la universidad lo importante es enseñar bien, formar ciudadanos y buenas personas capaces de desempeñarse en la sociedad, producir conocimiento original y relevante para el desarrollo social, y difundir la cultura.

La burocracia marca sus rasgos en cada vez más áreas del quehacer universitario y, al mismo tiempo, adquiere rasgos específicos en cada institución concreta donde ejerce su dominio. Por su tamaño y su presencia cada vez más mayores, en la universidad este grupo ha adquirido un estilo de conducta y una ética que podríamos caracterizar con argumentos diferentes, a los expuestos líneas atrás. El modo como opera la burocracia universitaria hace que la gobernanza padezca de tensiones con la actividad académica, que pueden llegar a trabar el buen desarrollo de esta última.

En la práctica, la burocracia tiene una dinámica que la impulsa a intervenir en la actividad académica, se apropia de la cultura institucional y la usa a su favor. En la universidad, la burocracia tiene rasgos éticos y una forma práctica de operar que obstaculizan la labor de quienes realizan las funciones sustantivas. Hay tensión entre una actitud conservadora de la burocracia sobre el manejo administrativo y político frente a una actitud favorable a la flexibilidad funcional que reclama el trabajo académico. Hay tensión entre las formas burocráticas de conducción y la pérdida de influencia de los académicos y de los cuerpos colegiados en la toma de decisiones sobre las políticas institucionales, elaboradas en los escritorios de la alta burocracia.

${ }^{2}$ Un libro que puede consultarse es el de Paul Du Gay (2012) en el que el autor hace una defensa de la burocracia como cuerpo fundamental para mantener un régimen democrático. 
Sugiere C.Wright Mills (2003) que la burocracia tiende a dominar los medios del quehacer académico en la universidad, a medida que se elevan la complejidad institucional y el costo de la docencia y la investigación. A medida que el trabajo de los académicos depende de la burocracia pierde su carácter verdaderamente autónomo, su libertad individual de crear. Y ello se debe a que las lógicas de uno y otro sectores son diferentes, aunque las lógicas de la burocracia y los valores en los que se apoya se imponen a la academia.

La burocracia universitaria tiene un hacer contrario al hacer de la academia. Y este es uno de los mayores problemas que puede enfrentar una universidad en su trayectoria histórica. Es una contradicción que puede eliminar los efectos positivos que tiene el conocimiento en el aula y en el cubículo. La burocracia trata a los académicos y a los estudiantes a partir de una visión individualista que le permite sobreponerse a la enseñanza y a la producción colectiva de conocimientos por la vía de implantar la competencia como medio para que los académicos ganen dinero y prestigio.

La burocratización de la academia se asocia a una relación de dependencia con la administración sobre la base de transferencias de recursos materiales y simbólicos, en virtud de lo cual los académicos mantienen una posición subordinada en el campus. En la universidad, la burocracia ejerce el poder, impone la forma y las formalidades a la esencia de la actividad, dispone de los instrumentos de dominación y hace política para reproducir el régimen en el que se asienta el gobierno universitario y su propia presencia.

En estos términos, la burocracia universitaria es un elemento clave para entender las prácticas políticas en la universidad, porque interactúa con profesores, investigadores, estudiantes y con los trabajadores que dependen de ella. Porque maneja lo cotidiano del gobierno universitario. Para analizar a la burocracia cobra importancia la cohesión y la identidad del grupo, además de su tamaño, que está vinculado a la complejidad y la división orgánica del gobierno universitario. Y desde una perspectiva sociológica, interesa analizar hasta qué punto la burocracia universitaria es permeable a los cambios de la institución, de la producción del conocimiento, o hasta qué punto los frena.

La preocupación analítica por la burocracia y la administración universitarias, entonces, emerge de varias inquietudes: la burocracia impone criterios a la actividad académica, estandariza su aplicación a una realidad diversa; la rutinización burocrática frena el ritmo de la producción o transmisión del conocimiento. También, hay inquietud debido a las dificultades que acarrea su carácter interpersonal en un ambiente donde el debate y la disputa por la razonabilidad ocurren día a día, frente a frente, a través del diálogo.

La burocracia en la universidad es un objeto de estudio porque puede poner trabas a la vida colegiada y a la participación de la comunidad académica 
en los cuerpos colectivos de decisión. También, porque la burocratización tiene implicaciones valorativas y políticas sobre los académicos y los estudiantes. (e.g. Blau y Meyer, 1987).

Por último, la organización universitaria en manos de una burocracia ineficiente impide tener una buena conducción académica y política de la institución. ${ }^{3}$ Estudiar a la burocracia permite reconocer relaciones de poder en el campus que de otra manera no aparecen en la superficie. El análisis de la burocracia toca de lleno el asunto del poder en una organización formal como la de la universidad pública en México.

Para entender el entramado político en el que está metida la burocracia universitaria es necesario acercarse a través de varias aproximaciones. La universidad pública en el país tiene un gobierno que funciona bajo un modo de operación burocrático. Es un modelo de gobierno que tiene similitudes estructurales en el conjunto del sistema universitario, dados sus vínculos de dependencia con el gobierno federal. Presenta semejanzas en cuanto a la gestión, porque el modelo ha sido impulsado por las políticas educativas del Estado mexicano, acercándose a lo que se denomina nueva gestión pública, enlazada a la planeación estratégica (Casanova, 2009).

Y, no obstante, en este modelo de gestión (y a un denominador común de actitudes y comportamientos), se descubre que la burocracia pertenece a un sistema universitario institucionalmente heterogéneo y estratificado, lo cual introduce distinciones en los rasgos de la burocracia, diferencias que son un punto a ilustrar en este texto. El supuesto es relevante porque la burocracia forma parte del sistema de poder universitario en cada una de las instituciones.

Comprender el ejercicio del poder en la universidad, entonces, está ligado a qué es y cómo funciona la burocracia. En este texto voy a discutir, primero, que la burocracia es un sector que no puede ser visto como un todo homogéneo. Descomponerla en sus partes puede ayudar a entender hasta qué punto las relaciones entre ellas hacen coherentes sus acciones y pueden existir identidades y lealtades que favorecen su acción frente a los demás grupos que integran la universidad. Aquí, vamos a sugerir una forma de distinguir los segmentos de la burocracia y discutiremos algunos significados de su división. Es un acercamiento inicial y exploratorio.

En segundo lugar, presentaré una reflexión sobre cómo se ha impregnado la burocratización en la academia, o sea, cómo una forma del hacer burocrático ha invadido la actividad académica y cómo en esa medida la atropella. En

\footnotetext{
${ }^{3}$ En el campo de los estudios organizacionales, lo relativo a la burocracia cobra un papel central. Un excelente repaso de las teorías organizacionales se encuentra en Ibarra (1999).
} 
tercer lugar, discutiré cómo la burocracia ha impuesto su poder sobre la academia para controlarla, para que se sujete a sus formas y normas de acción. Finalmente, daré unos comentarios y dejaré formuladas algunas preguntas que faltan de responder y que pueden encaminar trabajos futuros.

\section{La burocracia universitaria y sus fracciones}

La estructura sobre la que se organiza la burocracia en la universidad está dada por la distribución del personal entre unidades de la institución, subunidades, dependencias, departamentos, en cada una de las cuales hay posiciones ocupadas para realizar un trabajo mediante procedimientos estándar. La complejidad y la diversificación de tareas en una universidad se vincula a la diferenciación del sector burocrático.

El tamaño de la burocracia es una dimensión crucial porque el número de empleados indica menor o mayor cantidad de posiciones y mayor o menor complejidad del trabajo y de las relaciones que mantienen los segmentos de una burocracia entre sí y con sus jefes. Usamos esta perspectiva porque pensamos que el análisis de la burocracia debe realizarse atendiendo a las maneras en que se divide en la universidad. El tamaño, la composición del personal y la jerarquía que ocupa tienen que ver con los mecanismos de control que ejerce una fracción de la burocracia sobre otra y con los mecanismos de control que aplica la burocracia sobre los otros sectores que conforman la universidad.

No hay información suficiente sobre la burocracia universitaria; al menos no está disponible para consultarse de manera abierta. Lo que podemos decir habla de una realidad que puede ser observada y descrita hasta cierto punto, más bien en la superficie o a un nivel de profundidad mínimo. Pero hay que empezar aunque sea con datos puntuales que nos permitan describir y conocer por encima a este importante actor universitario que forma parte del conglomerado político de actores universitarios. Como se dijo, su crecimiento, su consolidación y su fortaleza política se han dado en los últimos lustros, a partir de políticas públicas que han estimulado su presencia y sus ganancias de poder.

En México se ha escrito sobre este grupo (e.g. Marquis, 1987), ${ }^{4}$ ligándolo a la vida política universitaria, cuando apareció el sindicalismo en las universi-

\footnotetext{
${ }^{4}$ Recientemente el autor de este trabajo escribió dos artículos en el Suplemento Campus, ¿Para qué nos sirve la burocracia Universitaria? México. Campus Milenio, Núm. 261, 21 Febrero, 2008, y Las fracciones de la burocracia universitaria, Campus Milenio, Núm.658, 25 Mayo de 2016.
} 
dades, que ha agrupado a los trabajadores administrativos y, en varios casos, a los académicos (Basurto, 2006). No vamos a ocuparnos de los sindicatos ni de la fracción de la burocracia sindicalizada; vamos a describir y, en lo posible, a interpretar el significado de los distintos segmentos que componen al grupo.

Señalé al principio que la burocracia universitaria es jerárquica. Puedo agregar que no he encontrado algún dato que indique cuál es su volumen en todo el sistema de universidades públicas, ni tampoco de sus fracciones. Lo que me parece, a partir de lo observado en varias universidades públicas estatales y una federal, es que los trabajadores de la administración universitaria suman tantas o más personas como el sector de los académicos de tiempo completo. En algunos casos el sector administrativo de la universidad, identificado aquí con la burocracia, puede llegar a tener más personal que el total de los académicos; ${ }^{5}$ la cifra es variable entre las instituciones, pero lo que se comenta es que el aparato burocrático-administrativo pesa en las decisiones que se toman en las universidades públicas.

La gran mayoría de esta fracción son trabajadores de base, que están en la administración central y en las dependencias universitarias. Son los que mayormente nutren a los sindicatos de trabajadores administrativos; realizan una buena cantidad de ocupaciones, las más de carácter manual en los servicios de limpieza y mantenimiento de la infraestructura. También desempeñan servicios de vigilancia e intendencia; hay operadores de transporte, y otros hacen trabajos de oficina, manejan y supervisan al personal de base. Hay una capa de este sector que hace trabajo secretarial. Entre los trabajadores administrativos de base están aquellos que operan en ventanilla para atender trámites de los estudiantes y de los académicos. Aquí, en este nivel, los usos y costumbres, y algunas prerrogativas sindicales, le ponen lentitud a los trámites y a la prestación de servicios. Un rasgo de este segmento, es que las incorporaciones al mismo se hacen mediante mecanismos particularistas, más por ayuda familiar en el sindicato que por sus capacidades para desempeñar el trabajo. Hay, en consecuencia, grupos que tienen una fuerte solidaridad y que se protegen en el descuido laboral.

Otro segmento de los trabajadores administrativos son los de confianza, que, por tanto, no están sindicalizados. Son una especie de clase media de la burocracia, porque auxilian a los directivos en el trabajo secretarial (personal

${ }^{5}$ Solo unos cuantos datos para ilustrar el punto. En la Universidad Autónoma Metropolitana, en sus primeros 10 años (1974-1984), la parte de los administrativos creció más que la del personal académico; al final del período había 1.4 administrativos por cada profesor. En la unAM, en el 2006, había 2.3 administrativos por cada académico de carrera; pero el total de administrativos sobre el total de académicos era de 0.56. Véase Marquis, (1987) y Buquet, et al. (2006). 
y confidencial); hay, igualmente, jefes de sección, secretarios que hacen labores técnicas, de unidad administrativa, labores de apoyo profesional (e.g. asesores, abogados, contadores, auditores) y secretarias particulares.

En los mandos medios de la administración existe la competencia por los puestos de este nivel, y hay cierta movilidad de las personas entre las dependencias, sus miembros conocen bien las entrañas institucionales y son, en parte, apreciados por ello. Desarrollan despotismo, contra estudiantes y académicos, y mantienen una actitud política dirigida a conservar o ganar privilegios: mantener el poder institucional sin cambios. Estimo que los trabajadores de confianza y los mandos medios deben representar de un 10 a un $20 \%$ de la burocracia universitaria.

Un último sector es el de la alta burocracia, que cubre a lo que se denomina funcionarios académico-administrativos. Son puestos de subdirector, secretario académico de dependencia, director de facultad, instituto, centro o programa, director general en la administración central, coordinador de subsistema, secretario general y rector. Los miembros de esta fracción deben representar una cifra aproximada de entre el 5 y el 10\% del total de la burocracia. En ellos recaen las tareas de planeación, evaluación, programación, presupuestación, conducción de cuerpos colegiados y labores políticas para mantener la estabilidad institucional. En fin, se trata de la capa directiva, aquella que tiene períodos de mando fijos; se mueve o cambia de puesto para que haya sucesión y se renueve la óptica de la conducción institucional, la propia burocracia y los entendimientos informales en el gobierno universitario.

Hemos señalado, desde hace algún tiempo (Muñoz, 2009), que el sistema de educación superior público es profundamente heterogéneo y estratificado. Hemos supuesto que este hecho debe tener alguna repercusión sobre las diferencias que conforman a la burocracia universitaria. Al interior de una institución, además, la burocracia se divide, como hemos insistido, en fracciones o segmentos.

Entre las peculiaridades institucionales se encuentra la división que se hace de los administrativos. Por ejemplo, en materia salarial, hay dos cuestiones: una, que las diferencias salariales entre fracciones de la burocracia varían entre las instituciones. La otra es que un mismo puesto tiene una remuneración distinta según la institución donde se labore. Encontré un estudio en el que se comparan cinco universidades públicas: dos federales y tres estatales (Vázquez, s/f). ${ }^{6}$ Se aprecia que las remuneraciones son distintas. Por

\footnotetext{
${ }^{6}$ Las estadísticas fueron presentadas en el trabajo de Lázaro Vázquez, (s/f). "La información viene de las páginas de transparencia de las universidades. Está presentada en cuadros y gráficas muy claros.
} 
ejemplo, en una universidad estatal, el auxiliar de servicios tiene un salario ligeramente más alto que sus pares en el resto de las universidades (Tabla 1).

Tabla 1

Salarios del Personal Administrativo de cinco universidades

\begin{tabular}{|c|c|c|c|c|c|}
\hline Puesto/IES & BUAP & UNAM & UAM & UAEM & $\mathrm{U}$ de guanajuato \\
\hline Secretaria & $\$ 4,924.00$ & $\$ 4,608.97$ & $\$ 6,791.71$ & $\$ 3,666.39$ & $\$ 4,788.98$ \\
\hline Bibliotecario & $\$ 4,775.16$ & $\$ 5,993.82$ & $\$ 11,418.75$ & $\$ 3,875.24$ & $\$ 6,506.57$ \\
\hline Técnico esp. & $\$ 5,647.22$ & $\$ 5,592.72$ & $\$ 9,216.28$ & $\$ 4,292.72$ & $\$ 6,442.13$ \\
\hline Chofer & $\$ 5,179.06$ & $\$ 4,848.94$ & $\$ 6,073.01$ & $\$ 3,805.57$ & $\$ 6,564.14$ \\
\hline Aux. de servicios & $\$ 4,061.28$ & $\$ 3,732.00$ & $\$ 4,461.31$ & $\$ 3,457.54$ & $\$ 4,745.11$ \\
\hline \multicolumn{6}{|c|}{$\begin{array}{l}\text { Tabla de elaboración propia con información de las páginas de transparencia de las IES. } \\
\text { Benemérita Universidad Autónoma de Puebla (BUAP), Universidad Nacional Autónoma de México (UNAM), Universidad } \\
\text { Autónoma Metropolitana (UAM), Universidad Autónoma del Estado de Morelos (UAEM), Universidad de Guanajuato (U de } \\
\text { Guanajuato). } \\
\text { Fuente: Vázquez, (s/f). Foro de la Educación Superior, Año 4, No.22.. }\end{array}$} \\
\hline
\end{tabular}

En otra comparación, se repiten en el análisis las dos universidades federales y se agrega una tercera. Repiten dos estatales y una federal del Tabla 1 queda fuera. La información estadística muestra que los salarios del personal administrativo son diferentes: en las tres federales los rectores ganan bastante más que en las dos estatales (van de 175828 a 55957 pesos). De nuevo, esto es un simple ejemplo de la diferenciación institucional, pero muy ilustrativo. Una tendencia semejante ocurre con los salarios de cargos como el de Secretario General, Directores y Subdirectores (las diferencias van de 150220 a 33 034). En las cinco universidades, los funcionarios y directivos ganan salarios distintos a igual cargo y entre ellos hay diferencias notables por nivel de importancia del cargo (Tabla 2).

Tabla 2

Salarios de funcionarios

\begin{tabular}{|c|c|c|c|c|c|}
\hline Categoría & BUAP & UNAM & UAM & IPN & U de guanajuato \\
\hline Rector & $\$ 70,955.42$ & $\$ 148,000.00$ & $\$ 87,820.01$ & $\$ 175,828.63$ & $\$ 55,957.64$ \\
\hline Secretario General & $\$ 55,877.75$ & $\$ 145,000.00$ & $\$ 88,698.87$ & $\$ 150,220.27$ & $\$ 53,129.41$ \\
\hline Director & $\$ 42,573.50$ & $\$ 45,863.10$ & $\$ 54,486.60$ & $\$ 95,000.00$ & $\$ 44,186.81$ \\
\hline Subdirector & $\$ 37,695.67$ & $\$ 33,034.07$ & $\$ 40,359.16$ & $\$ 39,573.34$ & $\$ 46,893.50$ \\
\hline \multicolumn{6}{|c|}{$\begin{array}{l}\text { Tabla de elaboración propia con información de las páginas de transparencia de las IES. } \\
\text { Benemérita Universidad Autónoma de Puebla (BUAP), Universidad Nacional Autónoma de México (UNAM), Universidad } \\
\text { Autónoma Metropolitana (UAM), Universidad Autónoma del Estado de Morelos (UAEM), Universidad de Guanajuato (U de } \\
\text { Guanajuato). } \\
\text { Fuente: Vázquez, (s/f). Foro de la Educación Superior, Año 4, No.22. }\end{array}$} \\
\hline
\end{tabular}


Finalmente, las diferencias salariales en la burocracia son significativamente distintas entre los niveles jerárquicos y entre las propias universidades. Por ejemplo, en una universidad estatal, la diferencia entre un salario de la burocracia de bajo nivel y el mayor en la burocracia de alto rango es de 14 veces. En una de las universidades federales las diferencias se extienden a 32 veces. $^{7}$

La burocracia universitaria de alto nivel, los funcionarios de la rectoría y los directivos de las dependencias académicas, forman parte de la elite institucional, junto con aquellos a quienes se les ha denominado como "aristocracia académica" (Clark, 1983). Unificados en esta fracción han podido mantener centralizada la toma de decisiones, controlar el manejo político interno, el cabildeo externo, la gestión y la distribución de los recursos económicos y la conducción de la administración. Puede decirse que los funcionarios de alto nivel de la burocracia se reclutan, en buena parte, de la aristocracia académica.

Los mandos superiores en la rectoría, y en las facultades, tienen la responsabilidad de tratar con los sindicatos y resolver los asuntos laborales; evitar cada año, en tiempos de revisión de contratos, en lo posible, las huelgas sindicales, y evitar las protestas estudiantiles. En otras palabras, el control político o la gobernabilidad, que también incluye a los académicos y sus actividades, es una de sus tareas más relevantes, porque está en la base de la estabilidad institucional y el ejercicio del poder. La alta burocracia formula los planes de desarrollo institucional, los ejecuta y les da seguimiento.

La elite de la administración ejerce liderazgo, impone proyectos académicos e intenta ligar el régimen de gobierno de un período rectoral a otro, recuperando la historia de la universidad en el marco de la sociedad en la que se ubica. Realiza un discurso para que la comunidad perciba como viables las propuestas de sus dirigentes y así ganar credibilidad.

\footnotetext{
${ }^{7}$ Este dato sirve para ilustrar que las fracciones de la burocracia son más o menos marcadas en cada una de las instituciones. Habría que relacionarlo con un conjunto de variables múltiples para encontrar una explicación rigurosa de las diferencias. Por lo que respecta al salario, podemos decir que el fraccionamiento alto, medio y bajo de la burocracia es posible de ser encontrado en todas las instituciones. Igualmente, se puede señalar que el modo de funcionamiento y dominación de la burocracia sobre la comunidad universitaria se encuentra probablemente asociado al tipo de relación que mantienen las distintas capas de la burocracia en cada institución concreta. En la Universidad Nacional Autónoma de México (UNAM), la burocracia se divide por mitad entre hombres y mujeres. La mayor parte $69.7 \%$ tiene estudios hasta la secundaria. Sólo el 8.5\% cuenta con la licenciatura o más (Buquet, et al., 2006, p. 221).
} 
La elite universitaria se mueve, entonces, entre símbolos, representaciones y significados que dan sentido al poder que ejerce en toda la comunidad. Y, por ello, la elite universitaria genera dominación para que su mando sea obedecido, para que la comunidad se comporte de una manera en que no confronte ni al grupo en el poder ni a su proyecto político.

En tanto que la academia se identifique con los principios políticos y educativos de la alta burocracia, con sus instrumentos de dominación, y los acepte, en esa misma medida jugará un papel de estamento subordinado y desarrollará una actitud conformista. La visión de la elite se tornará hegemónica (Ordorika, 2006).

La distinción de las fracciones de la burocracia universitaria lleva a pensar que cada una de ellas mantiene distintas relaciones con la comunidad, y que la comunidad percibe a cada una según que el trato sea directo o no. La idea de que los académicos mantienen actitudes políticas conformistas no es resultado de su práctica académica como tal, sino de la propia operación institucional que no les ha permitido participar y desarrollar una perspectiva crítica a la administración, debido al desarrollo de relaciones de dependencia de la propia academia con la burocracia que impide las manifestaciones de inconformidad e impone restricciones a su influencia.

\section{Burocracia y burocratización de la academia}

La burocracia es un régimen organizativo superior a otros. Como ventajas, la burocracia tiene (cito a Weber de nuevo) "[...] precisión, velocidad, certidumbre, conocimiento de los archivos, continuidad, discreción, subordinación estricta, reducción de desacuerdos y de costos materiales y personales, son cualidades que, en la administración burocrática pura, y fundamentalmente en su forma monocrática, alcanzan su nivel" (p. 47). La forma "pura" no existe en la operación real de una organización como la universitaria. Sin embargo, la complejidad y la expansión de la institución universitaria han implicado una mayor presencia de la burocracia y de mecanismos burocráticos para ser y desempeñarse como actor universitario.

No es una exageración decir que el ethos burocrático se ha infiltrado en todo el tejido social de la academia, de estudiantes y profesores. La burocracia tiene sus tiempos, marca los tiempos, por el manejo del dinero y por la influencia de la que goza, al margen de los tiempos de la academia. He aquí uno de los temas de mayor confrontación subjetiva en la vida universitaria,

${ }^{8}$ M. Weber: ¿Qué es la burocracia? Ver referencia al final del texto. 
que no se aprecia en la superficie, por la rutina y la inercia, pero que subyace en el quehacer cotidiano.

La burocracia se apoderó, para decirlo de algún modo, de la conducción de la universidad y con ello desarrolló una manera de ser donde la lentitud de la operación no es acorde con la existencia de una institución formada por varios actores cuya actividad es de ritmo rápido. Sin embargo, para la burocracia, con la que tratamos los académicos y los estudiantes, lo que existe no son actores que forman colectivos, sino individuos que intentan realizar una labor que depende de la administración. Frente a cualquier arbitrariedad, la persona en lo individual puede hacer muy poco. Se enfrenta a una estructura cuyas leyes de funcionamiento le son desconocidas; son reglas incorporadas a un cuerpo legislativo inmenso, que finalmente resulta incomprensible. ${ }^{9}$

Lo que sigue no hace referencia a un modelo; son rasgos generales sobre cómo es y cómo funciona la burocracia universitaria, que son más acentuados en algunas instituciones universitarias que en otras, que se adquieren probablemente por las ligas al poder y al gobierno de las universidades, al estilo de gobernar. Por ello, es importante reconocerlos, porque a través de la burocracia se realizan actos de gobierno que afectan la vida académica y las relaciones entre los actores universitarios. ${ }^{10}$ La burocracia y sus procedimientos se extienden y afectan la marcha de la academia, y este es un tópico de primer orden en la universidad. Es necesario, por tanto, discutir cómo opera la burocracia y sus efectos en la actividad académica.

La burocracia es rutinaria y opuesta a transformar sus prácticas y mecanismos de operación, lo cual es paradójico en una institución como la universidad sujeta permanentemente al cambio por la lógica de la proliferación del conocimiento y las tecnologías para producirlo y transmitirlo. ${ }^{11}$ En la academia, lo de hoy requiere flexibilidad operativa, por ejemplo, para armar y desarmar colectivos o laboratorios de investigación, seminarios de tesis; para la obtención de equipos e instrumentos; para acceder a las tecnologías de la información; para contar con bibliografía a la mano.

\footnotetext{
${ }^{9}$ Kafka señaló el absurdo de que el mundo de la burocracia es así porque lo hemos construido de esa manera. Y cada uno de nosotros, entonces, debería empoderarse para cambiarlo. En las obras de Kafka destaca el problema del individuo frente a la burocracia y la subordinación al poder. Véase Kafka, (2017) y El castillo (2014).

${ }^{10}$ Hace varias décadas, Carlos Marquis (1987) hizo una investigación sobre la burocracia universitaria que tiene que ser revisada y vuelta a revisar para hablar de este sector en la universidad, del autoritarismo de los rectorados y la participación de académicos y estudiantes en el corpus de gobierno universitario.

${ }^{11}$ Véase el libro de Paul Feyerabend (1986).
} 
Pero la burocracia universitaria con su lentitud, apegada al papeleo, es incapaz de resolver hasta lo más trivia. ${ }^{12}$ Un burócrata puede volver complicado un trámite sencillo, por incapacidad para tomar decisiones, debido a reglas e instrucciones de cómo realizar su trabajo mecánicamente; es sólo una parte del proceso y el todo no le despierta el menor interés. ${ }^{13}$

El académico, en su dependencia universitaria, trata con un funcionario de ventanilla, o de escritorio, en un pasillo, que puede no entender la importancia de rechazar el inicio de un trámite que, de ser el caso, obliga a la persona a reiniciarlo posteriormente, con la correspondiente pérdida de tiempo. El burócrata es la pieza de una maquinaria que funciona de forma piramidal y cuyo movimiento es supervisado desde arriba. La recepción de cualquier caso, en primera instancia, además, no significa necesariamente que será aceptado en un segundo nivel, una de cuyas funciones puede ser seleccionar aquello que se decidirá en un tercer nivel.

Por otra parte, el tiempo de ocurrencia de un proceso burocrático llega a desesperar cuando se alarga demasiado y exige al quejoso volver cada vez a preguntar qué pasa, dedicar un tiempo del que no dispensa porque tiene que trabajar. Y son tantos los requisitos que, para satisfacerlos, hay que hacer trámites en otras instancias burocráticas. Los académicos pasan horas y horas haciendo trámites, redactando informes, aprendiendo nuevas formas de declaración del trabajo hecho, formados en línea o esperando en despachos de funcionarios. Maximizar los resultados del profesor o el investigador supone una menor "carga burocrática", concepto que cubre, entre otros rubros, elaborar y entregar documentos para justificar los resultados de trabajo con plazos menores a un año, boletos de transporte, comprobar gastos de viaje o de trabajo de campo, organización de actividades académicas, permisos para asistir a eventos, etc. Desde luego no es una enumeración exhaustiva.

Una característica de la burocracia es que un trámite sigue un cauce pasando por varias oficinas. La prolongación de un trámite, o un rechazo que se sienta injustificado, provoca una frustración en el demandante de un servicio, que el burócrata de pasillo no resiente. La administración debe funcionar según un sistema exacto y puntual al interior del cual no debe permitirse que

\footnotetext{
${ }^{12}$ En la Benemérita Universidad Autónoma de Puebla (BUAP), por ejemplo, se dice que el estatuto orgánico aprobado en 1999 señala el mejoramiento del trabajo administrativo mediante su reestructuración y su profesionalización. Pero en la realidad, lo que se ha creado ha sido una enorme y costosa burocracia que muy poco ha influido en el desarrollo de la Universidad. Véase, Maldonado (s/f).

${ }^{13}$ En México es conocida la exigencia de presentar el acta de nacimiento para realizar una infinidad de trámites. El burócrata no puede dispensar su presentación aún cuando los datos se encuentren en la credencial de identidad oficial.
} 
un individuo aplique un concepto de servicio fuera del prescrito. El burócrata individual no tiene horizonte propio,${ }^{14}$ todo lo consulta y, de preferencia, lo transfiere. En estas condiciones el académico no consigue la respuesta esperada en el debido tiempo. O recurre a una autoridad de cierto nivel que agilice el trámite, o tiene que llenarse de paciencia para volver a intentarlo.

La organización administrativa de la universidad no otorga agilidad a los trámites; por el contrario, los hace más engorrosos con la apariencia de sencillez. Frente a la burocracia universitaria central, la burocracia de las dependencias académicas está sujeta a que le pongan una tarjeta roja o amarilla (como en el futbol soccer) en caso de no hacer bien el papeleo. El sistema se llama semaforización y produce tensiones entre distintas capas de distintos niveles en la burocracia, sin que nadie, ni críticos ni criticados, puedan hacer algo para cambiar una forma de administrar que se impone sin comentarios. El académico involucrado en un trámite no tiene por qué entender que la falta de respuesta es a causa de una mala relación de la burocracia central con la burocracia local de una dependencia.

La multiplicación de oficinas y la complejidad de la labor académica, por ejemplo en la investigación interdisciplinaria, han acarreado que el académico, además de profesar e investigar, tenga que llevar a cabo múltiples actividades que, finalmente, son exigencias resultado de decisiones que se toman en las oficinas de dirección administrativa, por la burocracia de alto y mediano niveles. Son actividades que la burocracia señala que no le corresponden hacer a ella, pero que son indispensables de realizar. Al académico le restan tiempo, pero no le cuentan en la medición del desempeño, así como tampoco se contabiliza el trabajo de campo en las ciencias sociales y en las humanidades.

La burocratización de la actividad académica ha implicado que los académicos tengan que hacer gestiones dentro y fuera de la universidad para conseguir financiamiento para sus proyectos. Tienen que llenar formatos explicando, en síntesis, lo que se va a hacer, administrar los gastos del proyecto (para lo cual depende de la burocracia) y justificarlos, a veces de manera sumamente detallada, por aquello de la desconfianza. Después se presentan resultados parciales y finales a los patrocinadores, que pueden ser oficinas universitarias que sólo revisan que se hayan realizado los informes del trabajo individual o de equipo. La burocratización de la academia se aprecia, igualmente, en los juicios que llevan a cabo las comisiones dictaminadoras, donde la definición final de un concurso de ingreso o de promoción a veces

\footnotetext{
${ }^{14}$ Recomiendo la lectura de un texto de Milan Kundera (1998) Shifter, Kafka, la burocracia. Descripción existencial del mundo moderno. Revista Vuelta, Núm 260, Julio de 1998.
} 
tarda meses, por el manejo burocrático de los recovecos jurídicos, en perjuicio de quienes concursan.

La burocracia no sólo impone criterios para evaluar, sino también tareas para hacer en la academia. Los investigadores y profesores, entre sus tareas, organizan eventos, revisan escritos y pruebas editoriales. Actualmente, además, requieren aprender a manejar las plataformas de las revistas, unas diferentes de las otras, para publicar artículos académicos, lo cual dificulta la labor de los académicos de mayor antigüedad y menos expuestos y socializados en estas tecnologías. Tienen además que pedir carta de recepción del artículo, dar seguimiento a las citas, entrar a los organismos que difunden la ciencia a niveles nacional e internacional (e.g. Researchgate), manejar blogs y páginas web individuales y de grupo, tramitar viajes a congresos para presentar las publicaciones, y un largo etcétera. Todos estos enredos para hacer academia los estimula la burocracia y terminan haciendo menos productivas las labores intelectuales.

En el texto de García Amado (2016) se llega a la conclusión de que mientras mejor sea un investigador, mayores ajustes tendrá que hacer a su tiempo, con un rendimiento de trabajo hacia la baja, mientras no cuente con auxilio para estas faenas. Da la impresión de que cuanto más amplia y compleja sea una burocracia, mayor la afectación del tiempo a la actividad académica. La organización del tiempo es una conquista que cada académico gana para sí, y es tal vez una de las cosas más difíciles, porque va en contra de las normas burocráticas para estructurar su actividad intelectual. De cómo se organiza el tiempo para hacer determinadas actividades depende el éxito académico.

Un sistema de evaluación que acredita instituciones, programas e individuos, insumos, procesos y resultados en la academia, se ha tornado en un laberinto auspiciado por la burocracia, en el que el académico se pierde por tener que estar rindiendo continuamente informes distintos, para distintas instancias de la burocracia, y probando todo lo que haya hecho para fines de medición del desempeño. Hay que juntar papeles y más papeles, toda suerte de comprobantes para integrar un expediente que nadie revisa o que se revisa por encima. La becarización ${ }^{15}$ de los trabajadores académicos está ligada al cumplimiento de requisitos establecidos por las burocracias para incrementar sus salarios. La política de deshomologación del salario académico, los instrumentos y la organización de la evaluación corren a cargo de la burocracia mayor.

${ }^{15}$ Término acuñado por Suárez (2008) para indicar que los académicos de tiempo completo tienen que concursar por becas complementarias al salario para tener un ingreso digno. 
El régimen que la burocracia ha aplicado a la academia implica que el trabajo se realice con una supervisión lo más estricta posible. Como ya señalé, es un régimen de desconfianza en los académicos en el que tienen que estar probando que trabajan y trabajan bien de acuerdo a indicadores definidos por la burocracia. Este es uno de los ejemplos de lo que ha significado la burocratización de la universidad, el control de la actividad de los académicos. En el fondo, el académico dedica más tiempo de lo normal a su trabajo para poder cumplir y no ser rechazado por los evaluadores. La burocratización ha individualizado el trabajo, ha exigido un "alto" desempeño y que sea el académico en lo personal quien se encargue de su propia renovación intelectual y de su capacidad profesional.

La burocracia que reina en las universidades públicas, en las de mayor tamaño, responde a las órdenes del jefe y una de sus funciones importantes, como parte de la llamada gobernanza, es mantener el control de los académicos por medio de la burocratización, incrementando la división del trabajo y pidiendo reportes de todo lo que se realiza o deja de hacerse.

La burocracia universitaria se ha consolidado en todas las universidades públicas, federales y estatales. La organización burocrática que se ha consolidado con la planeación estratégica, y una nueva forma de gestión que supuestamente propicia la competencia, no se tradujeron en procesos decisorios más ágiles y efectivos. La gobernanza, con el modelo de la nueva gestión pública, no ha influido en mejorar sustancialmente la práctica académica, pero sí en hacer a la burocracia más poderosa.

En general, la administración opera sin márgenes para producir e incorporar iniciativas de mejoramiento. Mover a la burocracia es difícil porque ha llegado a adquirir peso político, ha desplazado a la academia del centro de atención de la universidad, busca conseguir su propia autonomía y lucha por mantener sus puestos y privilegios. El espíritu de la burocracia recorre el campus; la desconfianza sobre los académicos, los trabajadores y los estudiantes se expande, lo cual enfatiza los mecanismos de control que pueden llegar hasta el ámbito político.

De ahí que, también en la burocracia universitaria, se haya introducido la política de deshomologación salarial y las becas al desempeño, para así restar inercias - que subsisten a pesar de todo - y poder controlar al trabajador. Los premios al desempeño han provocado que entre la burocracia se establezca una competencia insana (unos bloquean a otros) que genera tensiones que repercuten negativamente en el trabajo administrativo y en el andamiaje de la academia. 


\section{La burocracia y el poder sobre la academia}

El análisis de la burocracia cobra sentido sociológico porque es un conjunto social sobre el que descansa la organización administrativa de la universidad. Se agrupa, como dije, en una jerarquía en la que hay que cumplir determinadas obligaciones en cada nivel. La labor de los de menor rango está controlada o supervisada por los que ocupan cargos de mayor jerarquía y poder de mando. Entender esta forma de organizarse es crucial, entre otras cosas porque de arriba hacia abajo se crea una suerte de insensibilidad sobre cómo deben cumplirse los trámites y procesos administrativos; se exigen requisitos o documentos que no tienen en cuenta cómo opera la realidad concreta (siguiendo a Kafka [...]). Las acciones y operaciones no se ajustan necesariamente a las exigencias de la burocracia, aun en los trámites más sencillos.

Así, hay un hiato entre lo que pide la burocracia que se cumpla y la forma como se realizan diversos aspectos para organizar actividades académicas. La burocracia simplemente pide u ordena que se ciñan, a como dé lugar, a lo que se demanda, porque de otra manera no puede hacer su trabajo como se le ha indicado. Las opciones son que el académico se someta o renuncie a su proyecto docente o de investigación, o que lo lleve a cabo a modo de no lidiar con la burocracia. De cualquier forma, el académico sale perdiendo y, tal vez, la institución. Tal parece que la misión de la burocracia es complicarlo todo.

Con el devenir de la educación superior en México, el aumento en el tamaño de la población universitaria, una cada vez mayor complejidad organizativa de las universidades públicas y los aparatos del gobierno universitario - que integran a las oficinas centrales, coordinaciones y direcciones generales - se multiplicaron. Crecieron los presupuestos, los montos dirigidos a las tareas administrativas, y se instauró un sistema de control de la academia por la vía de las transferencias monetarias a programas y proyectos (e.g. el Programa de Mejoramiento del Profesorado [Promep]) instaurados y respaldados por el gobierno federal. La deshomologación salarial y las becas al desempeño, el manejo del estatus y el prestigio, la definición de la trayectoria - a la que los nuevos académicos deben aspirar - , vinieron a ser instrumentos de control de la academia. El concurso de selección para ingresar a la universidad, el rechazo estudiantil, la selección de planteles y carreras, han tenido un papel semejante. En todos los casos, el miedo y la incertidumbre han jugado a favor de la burocracia y le han dado ganancias de poder.

La acción de control estimuló una forma de gestión que promueve la competencia entre las instituciones y entre los académicos, y el cabildeo entre autoridades universitarias y del gobierno estatal y federal. Dotó de mayor poder a los rectorados porque son los que reciben o consiguen recursos, y 
quienes los distribuyen. Se desarrolló un aparato administrativo más grande y más fuerte políticamente, que terminó por sobreponerse a la academia.

El peso de la burocracia sobre la academia ha implicado cambios en el papel que juega la academia en la universidad, porque la división del trabajo en las tres funciones sustantivas quedó sujeta a criterios que se imponen a la academia, particularmente en los instrumentos de evaluación de su trabajo. Por ejemplo, en muchos informes ni siquiera se pide registro de las labores de difusión. La comunicación con la sociedad no está considerada en las políticas académicas. La burocracia le define a la academia su actividad en forma y tiempo, así mismo, la evaluación al desempeño y las comisiones dictaminadoras. Quien define las reglas para evaluar es quien tiene mayor poder (Bourdieu, 2000). La burocracia impone cosas que, en ocasiones, contradicen el principio de la libertad académica.

Del mismo texto de Weber (2008) ya citado, he tomado la idea de que la burocracia es un sistema de dominio social, un instrumento de gobierno y de administración que controla la actividad, a la que le impone un orden de acuerdo a sus criterios. En la burocracia quienes ocupan puestos de mayor rango en la jerarquía son autoridades que giran órdenes para ser obedecidas, lo cual es un atributo del poder. La orden recibida es indiscutible y orienta la acción del burócrata.

La misma actitud acrítica es exigida por la burocracia a la comunidad. Y una vez que la comunidad acepta comportarse de conformidad a los dictados de la burocracia, la legitima para que implante un sistema de dominación ${ }^{16}$ que subordina a los académicos y a los estudiantes, en el caso de la universidad, en sus relaciones con la administración. Esto es, la burocracia obtiene reconocimiento al ejercicio del poder y una posición para exigir obediencia; también para otorgar privilegios a quienes pertenecen al grupo de mayor nivel jerárquico en la administración y a quienes pertenecen a círculos afines o se identifican con los intereses del gobierno universitario.

La burocracia se integra en un sistema de dominación en el que se manda y se obedece conforme a las normas jurídicas establecidas en el corpus organizativo, a través de las cuales se logra la coordinación de la actividad según el tamaño de la institución y la amplitud de la división del trabajo en ella.

En las universidades públicas del país se localiza un problema trascen-

\footnotetext{
${ }^{16}$ Sobre la dominación se puede consultar a Pierre Bourdieu (1991). Hay que prestar atención al punto de dominadores y dominados, a la subordinación de estos últimos, y al juego del poder político y el capital simbólico vinculado con la legitimación del régimen político (por la vía del convencimiento y las percepciones, o, en su caso, por la vía de la fuerza). O de cómo los dominados aceptan el poder de los dominadores para ser.
} 
dente enclaustrado en una contradicción entre los principios de la burocracia y la lógica que sigue el trabajo académico. Hay una fuerte tensión entre una burocracia que busca controlar a los académicos y académicos que hacen lo conducente para no ser manipulados por la burocracia.

Para hacer menos visible esta contradicción, la burocracia formula reglamentos en los que se definen las comisiones evaluadoras del trabajo académico, que operan conforme a las normas que establece la burocracia. En dichas comisiones, las que dictaminan, la burocracia integra a académicos reconocidos que se incorporan a tareas en las que alcanzan un poder temporal, mientras dura el cargo, sobre sus colegas sometidos a juicio.

Al mismo tiempo, los dictaminadores se vuelven sumisos a las reglas burocráticas; con su participación justifican no sólo las reglas para el juicio académico, sino también las decisiones que se toman en las cúpulas burocráticas sobre cómo hacer y reconocer el trabajo académico. Es complejo llegar a percibir estas formas sutiles del ejercicio del poder de la burocracia, pero a lo largo del tiempo salen a flote y pueden ser percibidas por la comunidad.

Se puede señalar, en suma, que en la universidad pública conviven dos grupos movidos por diferentes proyectos y visiones, uno, el académico, cuyas aspiraciones institucionales se orientan por valores "democráticos", y otro, el burocrático, que se apega a una visión jerárquica en la que la administración ocupa un lugar más elevado y desde el cual se orientan la competencia, la eficacia, la eficiencia, y otros valores que derivan de la "nueva gestión pública". Por lo pronto, en lo que va del Siglo xxI, el dominio de la burocracia en la universidad se ha impuesto, así como sus repercusiones sobre la academia - anotadas desde varios puntos de vista críticos y perspectivas - para que se discuta la política de la educación superior y para definir si lo que tenemos debe o no continuar y, en su caso, cómo lo cambiamos.

\section{Comentarios finales}

La burocracia es un actor de la política universitaria; ha crecido y consolidado su fuerza política como resultado de los cambios acaecidos en las universidades públicas en los últimos lustros. Así mismo, es una parte importante del gobierno universitario; le corresponde actuar en medio de todas las tensiones provocadas en el cotidiano institucional, por las medidas que aplican los rectorados a la comunidad académica y aquellas que devienen de la lógica administrativa que ponen frenos a la academia. Las tensiones en la universidad tienen muchas causas, pero una de ellas surge por la desigual distribución del poder que favorece a la burocracia frente a la comunidad 
académica. Uno de los mayores desafíos para la universidad pública será que los académicos controlen a la burocracia para que ésta actúe con respeto, flexibilidad y reconocimiento, a la manera como se hacen la docencia y la investigación.

De la división de la burocracia en fracciones parece importante sugerir que el sector directivo es el que pone la ruta crítica, es el grupo donde se teje la política y se toman decisiones. Es desde donde se ejerce el mando sobre el conjunto de la burocracia y el destino de la institución; sus errores son muy costosos en términos institucionales. La fracción intermedia es aquella encargada de ejecutar las decisiones, los instrumentos y procedimientos administrativos, y la que está en constante interacción con profesores y alumnos. Es la encargada de exigir obediencia a medidas e instrumentos administrativos. Es un sector que produce y hace sentir las tensiones en la institución. Es un subgrupo que por vía de la organización jerárquica juega a la lealtad con el jefe y obedece sobre lo que tiene que hacer. Muestra sentimientos de poder sobre la academia. El sector más bajo de la burocracia es aquel que tiene como principio hacer como que trabaja, labora lo mínimo y genera muchas insatisfacciones con los servicios, como se ilustró, por ejemplo, en la encuesta de estudiantes de licenciatura en la UNAM ( Suárez, 2012). ${ }^{17}$

La forma de administrar la universidad, la presencia directa de la burocracia central por medio de reglamentaciones y de estandarización de criterios, ahí donde se trasmite y se produce el conocimiento, limita la posibilidad de que profesores e investigadores organicen su modo de trabajo de una manera que les permita ser originales, meterle talento y creatividad. La falta de innovación se debe, en buena medida, a los criterios que la burocracia impone para hacer el trabajo, a la exigencia de un alto índice de productividad, medido por unidades publicadas en revistas indizadas, número de cursos impartidos, y muchas otras cifras que los académicos pueden satisfacer sin que su producción signifique contribuciones a la ciencia o recomendaciones para solucionar un problema concreto.

La complejidad organizativa de las universidades también se aprecia en la actividad académica. Hay necesidad de una mayor interacción e intercambio de académicos de diversas disciplinas, de flexibilizar las posibilidades de integrar colectivos de trabajo para tareas de conocimiento específicas, que se desintegran al término de un proyecto. Se trata de crear espacio - por tiempo delimitado - een los que colabore personal académico proveniente de distintas unidades institucionales de la universidad; de aceptar publicaciones

${ }^{17}$ Los estudiantes de la UNAM manifestaron que a este grupo es al que menos confianza le tienen. 
colectivas; de estimular la recolección y elaboración de nueva información; de liberar al académico de tener que producir una cantidad determinada de artículos por año; de respetar las opiniones y sugerencias de los académicos para relacionarse con la administración; de fomentar la participación de los académicos en los medios de comunicación; de permitir que quienes hacen la academia fijen, explícitamente, sus tiempos, tipos y aplicación de resultados, así como el término de las tareas, la renovación de las mismas, etc.

En suma, el propósito para que la universidad siga un buen curso es fortalecer el espíritu de colaboración de la burocracia con la academia y que sea la academia la que defina el devenir institucional mediante su participación efectiva en los cuerpos colegiados. En lo que sigue, la universidad no puede darse el lujo de tener un rectorado que la comunidad perciba como fracasado debido a la excesiva burocracia y a los malos tratos de la burocracia con la academia, rebasado por el cada vez mayor número de quejas o de plano rechazado por la comunidad debido a la burocracia del poder y al poder de la burocracia.

Aseveraciones como las anteriores justifican el que se continúe el análisis político del gobierno universitario cuyo funcionamiento y estructura merecen discutirse para mejorar a la universidad pública. También vale la pena debatir hasta qué punto los instrumentos administrativos, impulsados por las políticas educativas del gobierno federal, han servido a los propósitos de conseguir gobiernos universitarios que operen con eficacia y eficiencia la conducción institucional. El ethos burocrático y las relaciones de la burocracia con el corpus académico no parecen ser propicias a un desarrollo institucional que permita sacar el mayor provecho de lo que hacen los académicos en las universidades.

Éste puede ser el motivo por el cual hay que volver a discutir cambios al modelo de gobierno universitario vigente en torno a la centralización de las decisiones académicas y el uso de los instrumentos administrativos que soporta un estilo burocratizado de gobierno, con el cual se sustentan sistemas de evaluación que deben cambiarse para liberar la creatividad de la academia. Mientras más centralizadas se encuentren las decisiones académicas, habrá un mayor control de la actividad de los académicos de parte de las autoridades que conducen la institución. Hay que dar pasos para desburocratizar la academia, laborar en un régimen de confianza y, dentro de criterios generales de desempeño, hacer posible una evaluación que contemple criterios específicos por área o disciplina del conocimiento. Que cada dependencia asuma la responsabilidad y el compromiso por su trabajo.

Los directivos de las dependencias académicas universitarias deben enmarcar sus acciones en las leyes generales de la institución y gozar de toda 
la confianza de la administración central, para que sean ellos quienes pongan límites y abran posibilidades de avance académico, en diálogo con los académicos que realizan los proyectos docentes y de investigación. El reto es pensar y establecer una organización que pueda coordinar el trabajo de muchos equipos que gocen de confianza y de relativa autonomía; caminar hacia una nueva ética académica acorde a la cultura del conocimiento en estos tiempos de la era digital, que sirva al avance de la ciencia y fuera de la universidad al bienestar social.

La gobernanza debe partir de un entendimiento de qué es, cómo se hace y cómo cambia la academia, para que en efecto se le apoye en sus funciones y cometidos, para que sus decisiones sean tomadas en cuerpos colegiados ad hoc, regulados por ley como parte del gobierno universitario de cuya eficiencia en el apoyo dependerá el éxito de la gestión. ${ }^{18}$

Finalmente, en las universidades públicas hay sectores de la burocracia que han desarrollado intereses propios, lo cual genera tensiones cuando se margina a los académicos de las decisiones institucionales de peso, cuando hay elecciones para escoger directivos, procesos en los que se ilustra la subordinación y la dependencia de la comunidad ante la administración. Frente a la burocratización de la academia, y de la universidad, habrá que minimizar la autonomía política de la administración central y local, generar contrapesos institucionales reales, realizar una gestión que sirva cien por ciento a los fines de la academia que es el centro de la vida universitaria. La universidad, organizada en cada dependencia en colectivos de académicos para hacer las tres funciones sustantivas, puede darle nuevos bríos, cobrar fuerza, para transformar a la institución. Es de crucial importancia instaurar un régimen político en la universidad donde la confianza sea la dimensión que articule esfuerzos.

Cierro el texto con lo siguiente: ¿los directivos universitarios tendrán condiciones y posibilidades de hacer reformas para que la burocracia no subordine a la academia? ¿Se puede cambiar la ecuación para que la burocracia esté al servicio de la academia? ¿Qué tanta carga burocrática pueden seguir soportando los académicos? ¿Cuáles son los límites de la burocracia y la burocratización ante las necesidades de expansión institucional? Nos hacen falta más preguntas y más investigaciones.

${ }^{18}$ Tierney (2004) ha coordinado un libro en el que se discuten distintas perspectivas: académica, administrativa y política, sobre la gobernanza institucional en las universidades. En el capítulo elaborado por él se pone énfasis en los aspectos culturales como un factor de la mayor relevancia para entender cómo se orquestan las acciones que subyacen a la dirección y la administración de las universidades. Véase Tierney, (2004). 


\section{Referencias}

Blau, Peter y Marshall Meyer (1987). Bureaucracy in modern society. New York: Random House.

Basurto, Jorge (2006). La vida política del Sindicato de Trabajadores de la UNAM. México: IIs de la UNAM.

Bourdieu, Pierre (1991). El sentido práctico. Capítulo 8, "Los modos de dominación" (pp. 205-215). Madrid: Ed. Taurus.

Bourdieu, Pierre (2000). Intelectuales, politica y poder. Argentina: EUDEBA.

Buquet Corleto, Ana; Cooper, Jennifer A.; Rodríguez Loredo, Hilda; Botello Lonngi, Luis (2006). Presencia de mujeres y hombres en la unAM: una radiografía. México: PUEG-UNAM.

Casanova, Hugo (2009). "La universidad pública en México y la irrupción de lo privado". En Muñoz, H. (coord.) La universidad pública en México. México: SES, UNAM; Miguel Ángel Porrúa.

Clark, Burton (1983). El sistema de educación superior. México: Nueva Imagen.

Du Gay, Paul (2012). En elogio a la burocracia. España: Siglo XXI de España editores.

Feyerabend, Paul (1986). Contra el método. Esquema de una teoría anarquista del conocimiento. Madrid: Editorial Tecnos, S.A.

García Amado, Juan A. (2016). "Investigación Universitaria y Burocracia (o de cómo algunas instituciones se suicidan)". Almacén de Derecho. Newsletter 18, junio.

Ibarra, Eduardo (1999). "Los saberes de la organización: etapas, enfoques y dilemas". En Carlos Castillo (coord.). Economía, organización y trabajo. Madrid: Ed. Pirámide.

Kafka, Franz (2014). El castillo. España: Alianza Editorial,

Kafka, Franz (2017). El proceso. España: Editorial Planeta.

Kundera, Milan (1998). "Shifter, Kafka, la burocracia. Descripción existencial del mundo moderno". Revista Vuelta, número 260, julio.

Maldonado Herrera, Pascual (s/f). "La Burocratización de la BUAP: su Estatuto Orgánico". Foro de Educación Superior, Revista electrónica del Programa de Estudios Universitarios, Año 6 No. 29. México: BUAP.

Marquis, Carlos (1987). Democracia y Burocracia Universitaria. México: uAm-Iztapalapa.

Revista electrónica del Programa de Estudios Universitarios. México: BUAP

Muñoz, Humberto (2008). “Para qué nos sirve la burocracia Universitaria?” Suplemento Campus, número. 261, 21 febrero. México.

Muñoz, Humberto (2009). "Las universidades públicas: política, diferenciación y desigualdad institucional. En H. Muñoz (coord.). La universidad pública en México. México: SES y Miguel Ángel Porrúa.

Muñoz, Humberto (2016). "Las fracciones de la burocracia”. Suplemento Campus, número 658, 25 mayo. México.

Ordorika, Imanol (2006). La disputa por el campus. Poder, política y autonomía en la UNAM. Seminario de Educación Superior y Centro de Estudios sobre la Universidad y la Educación. México: unAm-Plaza y Valdés. 
Suarez, María H. (2008). "De becas y otras precariedades". Suplemento Campus Num. 260, 14 Febrero, 2008. México.

Tierney, William (2004). “Improving academic governance: utilizing a cultural framework to improve organizational performance" en W. Tierney (ed.) Competing conceptions of academic governance: negotiating the perfect storm. USA: The Johns Hopkins University Press.

Weber, Max (2008). Economía y Sociedad. Esbozo de Sociología Comprensiva. México: Fondo de Cultura Económica.

Weber, Max (2017). ¿Qué es la burocracia? http://www.ucema.edu.ar/u/ame/ Weber_burocracia.pdf 